\title{
Harmonious on Information Environmental and Environmental Accounting Control
}

\author{
Yali Wen \\ College of Zhuhai, Beijing Institute of Technology, Guangdong Province, China \\ txcf2000@163.com
}

\begin{abstract}
Keywords: Environmental accounting control; Information environmental control; Ecosystem equity; Environmental cost; Harmonious
\end{abstract}

\begin{abstract}
Because the accounting control has the fundamental and realistic features in the firms, so the environmental accounting is put outward to meet this need in the research. This research uses the accounting control thoughts and means to establish the environmental accounting control mechanism in governmental level and firms' level with main point of environmental control and the objective of life security. What is more, this research has designed the environmental accounting control to illustrate the environmental accounting control system. This research advances that the environmental accounting control can coordinate with the information environmental control, but the premise is that the information should have the regular control, and not the irregular control. The conclusion can help the information and firms improve their environmental control behavior.
\end{abstract}

\section{Introduction}

The theoretical basis of information environmental control originates from the classical economic theory, which is regarded as the basic theory of classical economics. As a representative of information regulation and self-regulation of enterprises, the external information environment control and enterprise internal environment management should be combined to play a role. Senden (2005) [1] think that self-regulation and information regulation is a kind of interactive, mutually soluble, complementary relationship, self-regulation is conducive to the extension of the function of information regulation and play, to make up for the lack of information regulation, and information regulation can provide impetus and institutional guarantee for self-regulation. But actual research, the two are strictly separated, Although Toshi H.Arimura (2008)[2] study shows that the information's environmental regulation does not weaken the role of ISO14001, and information command regulation and voluntary regulation can coexist, but did not link specific research links between the two is what, also did not give the impact of these regulations on corporate environmental performance.

The emergence and development of foreign environmental accounting can be divided into four stages : (1) Environmental impact into accounting horizons stage (1950s and 1960s), at this stage, due to the occurrence of industrial pollution events occur and environmental pollution event of legal proceedings, environmental litigation loss failure of economic compensation and environmental restoration costs become elements of enterprise accounting, corporate environmental awareness has increased spending on environmental are also included in the content of accounting. (2) Environmental accounting embryonic stage (Twentieth Century seventy or eighty). In 1975 in the UK Accounting Standards Board issued the "report", the social responsibility problem to the public a big part and environmental problems [3]. (3) The establishment and development of environmental accounting (1990s), at this stage, the world's large enterprises have voluntarily disclosed environmental information. In accounting, some elements of the environment began to appear relatively independent processing mode; the establishment of basic concept and mode of environmental accounting; environmental auditing is gradually built up [4]. (4) The rapid development phase of environmental accounting. At this stage, the environmental accounting theory by governments and business circles agree that environmental accounting methods have been widely used. Each country has set up the environmental 
accounting standards, such as the United States, Japan and other countries have introduced relevant laws and accounting standards [5].

As everyone knows, the information has been the main body of environmental control in our country, this paper also fully affirmed the important role of information environmental control. Environmental accounting control can play an effective role in close coordination with the information environmental control will play a vital role. Therefore, this paper is mainly to solve the coordination problem of environmental accounting control and information environmental control.

\section{Mechanism of Governmental Environmental Control}

Daily control refers to the environmental control of the main body of the enterprise through the legal and economic means and routine control, have certain procedural, its outstanding characteristic is routine, usually have specific laws and regulations as the basis, appear what circumstance with what kind of method for processing, basic will not be difficult to solve the problem. Typical daily control includes two kinds of control mode, are respectively formulate laws and regulations and establish control measures based on market economy.

Although there are many disadvantages, but the implementation can always achieve a certain effect, the same, the information also pay a certain cost. The cost that the information pays to implement the routine control is proportional to the strength of the control, and the complexity of the control object. Because it is a routine control, control content and means are relatively fixed, therefore, each time the implementation of control efforts to pay roughly the same. And the total daily control of the information and the number of enterprises or the size of a positive relationship, from a long-term perspective, the information's daily control of the track and the number or size of the changes in the number or size of track. Because there is no law to follow the change of the number or size of enterprises, therefore, it belongs to the random change of time, therefore, the daily control of the information is also random and continuous change. That is:

$$
G_{1}=g_{1}(t)
$$

$\mathrm{G}_{1}(\mathrm{t})$ is a function of time $t$, and it is a constant greater than zero. That is, diagram of curve is a function of time $t$, and not statistical data or the routine check function. The reason is that both of which are difficult to achieve real decision-making basis for the role, in fact, daily control efforts is a random function of time.

In addition to the daily control, the information's environmental control of the enterprise there is another kind of control is beyond the routine control, we call the exception control. Because the current daily environmental control is not enough to solve all problems, especially when the enterprise and the information's information asymmetry is more and more serious, environmental events will appear. In general, environmental events are a result of qualitative change of information to control the deviation of enterprise environment change. And as the information often use the exception control to make up for such control deviation, such as mandatory large-scale inspection, improve the standard and increase the intensity of punishment. Each time an environmental event occurs, the exception of the control intensity will be upgraded, but there will be a relatively stable period between the two upgrades, to maintain a certain degree of control. But to the next environmental events, the exception of control efforts will be straight up, and later to maintain a higher level of control, from the trajectory to see, similar to the ladder like. We use $\mathrm{g} 2(\mathrm{t})$ to express exception management. That is:

$$
G_{2}=g_{2}(t)
$$

$\mathrm{G} 2(\mathrm{t})$ is a step function, namely the piecewise function, mainly depends on the strength of the environmental events for additional control, in general, g2(t) will be as environmental events happened from low level to a higher level, also can reduce or even not as environmental events in a certain period dropped to a low position. $\mathrm{G} 2(\mathrm{t})$ has two limit values, the minimum is zero, that is no exception to control, the highest for the information to maximize control maximum deduction for daily control, is $\max \left(G(t)-g_{1}(t)\right)$, including $\mathrm{G}(\mathrm{t})$ on behalf of the information control over all the time. Therefore, $\mathrm{g} 2(\mathrm{t})$ specific functional form is: 


$$
g_{2}(t)=\left\{\begin{array}{l}
0 t_{1} \leq t<t_{1+m} \\
T_{1} t_{1}+m \leq t<t_{1+m+n} \\
\cdots \cdots \\
\max \left(G(t)-g_{1}(t)\right) t_{1}+m+n+w \leq t<\infty
\end{array}\right.
$$

To sum up, the total control of the information $\mathrm{G}(\mathrm{t})$ is the sum of the daily control efforts and the exception of control efforts. That is:

$$
G(t)=g_{1}(t)+g_{2}(t)
$$

Therefore, the function image of the total information control is a superposition of $\mathrm{g} 1(\mathrm{t})$ and $\mathrm{g} 2(\mathrm{t})$ function images. It is worth noting that the daily control efforts and the exception of control efforts in the information's total control of the proportion of the time change and change. Generally speaking, in the short term, total information control $\mathrm{G}(\mathrm{t})$ is mainly embodied in the change of daily control, exception control efforts to maintain stability in the short term; and in the long run, due to the exception control jump is relatively large, in comparison, daily control changes little. Therefore, overall performance is exceptional efforts to control changes.

\section{Control Thought-Oriented to Subsistence}

Since the double-entry bookkeeping produce, accounting control content relatively stable, namely possession of property, the value of investment property and equity value status. Therefore, the object of modern accounting control is the owner, the creditor investment security and increasing the value of the funds, regardless of which particular control method is used, such as budgetary control, standard cost control, accounting control and responsibility control performance evaluation, its main purpose is to ensure that the interests of the property investment's value, namely the problem of profit maximization. This kind of "equity-based" thinking in modern accounting has been an absolute dominance of the world economy has an indelible role, but at the same time, its shortcomings are increasingly apparent.

The core of modern accounting control is financial performance, and financial results have a guiding role for accounting control. Whether a single indicator or a comprehensive indicator as a measure of financial performance of enterprises, will give the business operators to provide a reference to the important decision basis. Any decision of the operator will point to the final financial indicators, in addition, the financial performance is also an important reference for the operator to control the post. Therefore, environmental performance must be business operators need to focus on the index of, especially under the guidance of the idea of the "the right to survival ", combined with the ecological interests, to build a modern enterprise environmental performance indicator suitable for. The guiding role of environmental performance indicators is mainly in the implementation of the specific implementation, the enterprise all decision-making behavior should be around the environmental performance indicators. Therefore, the guiding role of environmental performance is important for regulating the environmental behavior of enterprises and the effective control of the environment. However, due to the lack of existing accounting technology, the environmental performance needs to be a certain compromise. Second, the accounting control should reflect the promotion of environmental performance, and reflects the coordination with the information environmental control. That also means that has certain effect on the reduction of the cost of accounting control design enterprises to cope with the, and the information regulation according to corporate environmental control information, regulatory costs to less than of the environmental cost control of information. Assuming that the information can bear the maximum cost for $\mathrm{C}$, the maximum number of acceptable environmental events for $\mathrm{S}$, including $\mathrm{g} 1(\mathrm{t})$ on behalf of daily control efforts, $\mathrm{A}(\mathrm{t})$ on behalf of the environmental accounting control. In terms of information environmental control, does not have the enterprise environment control information, unit control cost of daily control as $\mathrm{K} 1$, each environmental event cost of exception control as $\mathrm{K} 2$, then information environmental cost for: 


$$
\left\{\begin{array}{l}
C_{G 0}=g_{1}(t) k_{1}+\sum S_{i} k_{2} \\
\text { s.t.: } k_{2}>k_{1}, \sum S_{i} \leq S
\end{array}\right.
$$

Environmental events will not happen, or very few, can be ignored in the case of enterprise environmental control information.

$$
C_{G 1}=g_{1}(A(t)) k_{3}
$$

Among them, $\mathrm{k} 3$ is the unit of daily control costs in the context of environmental control information. In environmental control information, should provide a good basis for decision making to the information, on the basis to improve the efficiency of supervision, the total cost also compared to no environmental control information to be small, namely: $\mathrm{CG} 1<\mathrm{CG} 0 \leq \mathrm{C}$, thus:

$$
\left\{\begin{array}{l}
g_{1}(t) k_{1}+\sum S_{i} k_{2}-g_{1}(A(t)) k_{3}>0 \\
\text { s.t.: } k_{2}>k_{1}, \sum S_{i} \leq S
\end{array}\right.
$$

In the enterprise environment control, when the enterprise does not establish the environmental accounting control, its cost is:

$$
C_{E 0}=e\left(g_{1}(t)\right) v_{1}+S_{i} v_{2}
$$

Among them, $\mathrm{v} 1$ is the unit cost companies comply with the information routine control, $v 2$ is the unit cost of the processing environment event.

When companies establish environment accounting control, the cost is:

$$
C_{E 1}=e\left(g_{1}(A(t))\right) v_{1}+A(t) v_{3}
$$

The use of environmental accounting control, to deal with the promotion of enterprise performance, mainly reflected in the cost savings of enterprises, that is CE1 $\angle \mathrm{CE} 0$. Specifically we have:

$$
\Delta C=C_{E 1}-C_{E 0}=e\left(g_{1}(A(t))\right) v_{1}+A(t) v_{3}-\left(e\left(g_{1}(t)\right) v_{1}+S_{i} v_{2}\right)<0
$$

According to the properties of e function, it can get:

$$
\left(g_{1}(A(t))-g_{1}(t)\right) v_{1}+A(t) v_{3}-S_{i} v_{2}<0
$$

Can be seen from the above equation (11), decided to reduce the cost of two factors, one is the detailed form of the function $\mathrm{A}(\mathrm{t})$, that is to say to specific forms of environmental accounting control determines the cost reduction; another decision to adopt environmental accounting control pays the cost and environmental events comparisons between the cost of treatment is typical of the cost benefit principle. These two factors in A ( $\mathrm{t}$ ) plays a crucial role, in addition to meet the conditions of the type (11), but also by the type (10) constraints. Third, the calculation must be simple environmental performance index. The purpose is to use easy to understand, for enterprise operators can clearly analyze the factors which lead to the change of environmental performance indicators, and make corresponding improvement measures for these changes.

\section{Control Coordination in Environmental Accounting}

In the absence of environmental accounting control, the efforts on information environmental control and corporate environmental control were used $\mathrm{G}(\mathrm{T})$ and $\mathrm{E}(\mathrm{T})$, which $\mathrm{t}$ represents the time variable.

$$
G(t)=g_{1}(t)+g_{2}(t)
$$

In the enterprise environment control, due to the lack of self - style environmental control behavior, therefore, mainly by the external information environmental control of the drive. But information environmental control includes two kinds of control of corporate environmental control behavior is not the same, the daily environmental control compared with the exception of enterprise environment control to be small, especially the more serious environmental degradation, environmental incidents occurred frequency is larger, the information mainly depends on the exception of environment control under, the enterprise is mainly due to the influence of from to exceptional environmental control g2(t). Therefore, the enterprise environment control function:

$$
E(t)=e(G(t))=e\left(g_{1}(t)+g_{2}(t)\right)
$$


Among them, $\mathrm{e}(\mathrm{x})$ function is a function of downgrade, that is, to reduce a number of the original amount. Since the information environmental control is not based on environmental accounting information, so the enterprise's response is negative, its strength is smaller than the information environmental control, we used to resist function $D(t)$ is represented companies resist outside information control the "effort", using this function allows external routine environmental control efforts to reduce, but cannot reduce the environmental exceptions efforts to control the information. In general, with increasing time to withstand the daily efforts to control the extent of the information will be increasing, that is, $\mathrm{D}(\mathrm{t})$ is an increasing function. Thus, the formula (13) can also be written as:

$$
E(t)=e(G(t))=e\left(g_{1}(t)+g_{2}(t)\right)=g_{1}(t)+g_{2}(t)-D(t) \quad(14)
$$

If the information truly effective environmental control of the enterprise, the marginal rate of information efforts to improve the control environment and corporate environments improve the control rate should be equal. We divide short and long term to discuss the issue.

Through the study on the mechanism of information environmental and environmental accounting control, it is found that the coordination of both is an important condition to ensure the effect of environmental control and use theoretical models and empirical data to analyze the coordination of both, for the subsequent environmental accounting control mechanism is established to provide theoretical basis. Specific conclusions are as follows: (1) the specific design of the environmental accounting control directly determines the coordination with the information's environmental control. (2) changes in information environmental control helps to improve coordination between the two. (3) environmental accounting control can give full play to its basic control function. Environmental accounting control not only solved the theory of accounting control in environmental control, but also provided a powerful reference for the combination of macro and micro environmental control mechanism between central and local governments.

\section{Acknowledgement}

Social sciences planning project for 2014, 12th five-year plan of Zhuhai philosophy and social sciences, study on evaluation and path of low carbon city construction in Zhuhai city (ZX-2014-007). Research project of archives bureau of Guangdong Province, research on the design of the electronic management system of accounting archives under the big data (YDK-126-2015).

\section{References}

[1] Linda Senden. Soft law, self-regulation and co-regulation in European law: where do they meet? Electronic Journal of Comparative law, vol.9.2005, pp.20-28.

[2] Toshi H.Arimura et al. Is a voluntary approach an effective environmental policy instrument? A case for environmental management systems. Journal of environmental Economics and Management, vol.55.2008, pp.281-295.

[3] Wiseman,J..An evaluation of environmental disclosures made in corporate annual reports. Accounting, Organizations and Society, vol.7. 2012, pp.553-563.

[4] Neely, A., Gregory, M., Platts, K. Performance measurement system design: a literature review and research agenda. International Journal of Operations and Production Management, vol.15.2015, pp.80-116.

[5] Pattern, Dennis. The relation between environmental performance and environmental disclosure: A research note. Accounting, Organization, and Society, vol.27.2012, pp.763-773. 